\title{
Vertical Foreclosure in Video Programming Markets: Implications for Cable Operators
}

\author{
HAL J. SINGER * \\ Criterion Economics, L.L.C. \\ J. GREGORY SIDAK \\ Georgetown University Law Center
}

\begin{abstract}
This paper argues that a cable operator with sufficient market power in the downstream multichannel video programming distribution (MVPD) market can deny access to unaffiliated programmers, resulting in an upstream programming rival's exit or impaired dynamic efficiency. Further, market dominance by cable operators may harm consumers of video programming through higher prices and less choice in the downstream MVPD market. The reason is that as unaffiliated video programming becomes affiliated programming, the latter is then withheld from rival MVPDs. This analysis is then applied to the recent acquisition of Adelphia by Comcast and Time Warner.
\end{abstract}

\section{Introduction}

Content discrimination occurs whenever a cable operator denies carriage based on the affiliation of the programmer. A vertically integrated cable operator engages in content discrimination against an unaffiliated programmer if the gains from that strategy (in terms of greater affiliated programming sales) exceed the downstream losses (in terms of fewer cable subscribers). The cable operator is willing to incur downstream losses both to weaken the unaffiliated programmer and, in a dynamic context, to send a signal to prospective entrants that it drives a hard bargain. The ultimate objective of such a strategy is to extend market power into the programming market and to maintain market power in the distribution market.

Unlike Internet content, which is generally national or international in its appeal, many forms of video programming are local. This particular characteristic of certain video programming, such as broadcast television news or coverage of a local sports team, makes the carriage of such programming susceptible to foreclosure strategies, as the content provider depends critically on the local multi-channel video programming distributor

* Contact author. Criterion Economics, LLC, 1620 Eye Street, NW, Suite 800, Washington, DC, 20006, United States. E-mail: hal@criterioneconomics.com We thank David Frederick and Evan Leo for helpful comments and Bradford Lyman and Seth Neidermayer for research assistance. We assume responsibility for all errors. 
(MVPD). In the case of regional sports networks (RSNs), consolidation of downstream market share can allow the vertically integrated cable operator to more credibly commit to its foreclosure strategy. In particular, an increased downstream footprint implies that future benefits from foreclosure are larger, as the cable operator can sell its affiliated RSN to a larger base of customers. Sports programming is a special case given its strategic importance to MVPDs (for example, FCC, 2002a).

In addition to assessing the benefits, a vertically integrated operator also considers the costs of content discrimination. There are several reasons why the costs of content discrimination could be small. First, the cable operator's customer incurs high switching costs to follow his or her preferred content to another platform. When video service is bundled with other offerings, such as broadband Internet access and telephony, these switching costs are even greater. Second, a cable television customer will not incur these switching costs so long as there is a non-trivial probability that the vertically integrated operator and the unaffiliated RSN will eventually reach an agreement. After the disputed content at issue is carried, the consumer regrets having incurred the switching costs.

It is clear how content discrimination harms unaffiliated content providers. By denying the unaffiliated RSN access to more cable homes in a given geographic market, the operator ensures that the RSN cannot achieve certain economies, and at worst, cannot achieve minimum viable scale. If the RSN cannot generate sufficient revenues to pay down the fixed costs of acquiring the rights to televise the games, the RSN will be forced to exit the market, resulting in complete foreclosure. At that stage, the cable operator can acquire the content outright. What is not clear is how content discrimination harms consumer welfare. Stated differently, even if the vertically integrated cable operator successfully induces the rival content provider to exit and thereby secures the local sports programming, it is not clear that the price that consumers pay for the programming is necessarily higher or that output is lower.

After a vertically integrated content provider secures the regional sports programming, it can proceed to engage in conduit discrimination - that is, it can refuse to supply that programming to a rival downstream MVPD. The most common rival MVPDs are direct broadcast satellite providers (DBS), although telephone companies such as AT\&T and Verizon have recently entered the MVPD market. In addition, multi-channel video programming is already distributed over cellular telephone handsets in some countries and is expected to become more prevalent in the United States. For content discrimination (followed by conduit discrimination) to lead to higher cable prices, it must be the case that rival MVPDs without access to the local sports programming cannot constrain cable prices to the same degree as MVPDs with access to local sports programming. Although there is little direct evidence in support of this proposition, some evidence suggests that lower DBS penetration leads to higher cable prices (General Accounting Office, 2003, p.11). Thus, to the extent that content discrimination results in lower penetration rates for rival MVPDs, content discrimination can be connected to higher cable prices. Other evidence shows a price-disciplining effect of DBS entry generally of roughly \$4 per month (Goolsbee and Petrin, 2004; Wise and Duwadi, 2005, p.679). In its 2004 Cable Pricing Survey, the Federal Communications Commission (2005c) found that for communities in the "high DBS penetration subgroup" (defined as two DBS providers representing at least 15 percent of total MVPD subscribers), the monthly cable rate and price per channel were, respectively, 3.7 percent lower and 2.6 percent lower than those averages for the noncompetitive group. 
The relevant question for regulators is how best to protect consumers against these forms of discrimination. With a requirement to provide rival MVPDs access to affiliated local programming, the vertically integrated operator could not limit its in-region DBS penetration rate through conduit discrimination. This requirement by itself may or may not deter the vertically integrated cable operator from refusing to deal with rival upstream programmers (see Supreme Court, 2004; Sidak, 2006) as content discrimination may still be profitable in isolation. After the RSN is induced to exit, the regulator must then establish an "access price" at which the vertically integrated cable operator must make its affiliated local programming available to rival MVPDs. But only independent sports programmers can provide a true "arms length" price for programming. The difficulty in establishing an efficient "access price" suggests that the discrimination problem should be addressed at both the upstream and downstream levels.

One can use the theoretical framework described above to assess the competitive effects of the now-consummated acquisition of Adelphia Communications Corporation by Comcast Corporation and Time Warner Cable Inc. on the local markets for sports programming. In particular, Comcast and Time Warner acquired cable systems within the Adelphia network, and Comcast and Time Warner engaged in a series of system swaps of their cable properties. The acquisition consolidated Comcast's downstream market power in two local markets in which Comcast was vertically integrated into sports programming: Washington, D.C. and Baltimore. The FCC (2006b) approved the merger subject to several conditions in July 2006.

One key merger condition was a requirement that Comcast agree to permit MidAtlantic Sports Network (MASN), which owns the television rights for both the Washington Nationals and Baltimore Orioles baseball teams, to enter into binding arbitration with Comcast to resolve a dispute that had previously left Comcast's cable customers in the Washington, D.C. area unable to watch most Washington Nationals games (Lenke, 2006). On August 5, 2006, only two weeks after the FCC's merger conditions were announced, Comcast agreed to carry MASN (Mohammed and Heath, 2006). Under the terms of the agreement, 1.6 million Comcast subscribers in the Baltimore-Washington region were able to view the Nationals games beginning in September 2006, while another 600,000 people in more distant parts of western Maryland, Virginia, Delaware and Pennsylvania would get access to the Nationals games over a twoyear period (Mohammed and Health, 2006). On August 12, 2006, Comcast increased its monthly service fee in Washington, D.C. by $\$ 2$ per customer, citing its carriage agreement with MASN as the primary justification for the rate increase (Mohammed, 2006). MASN acknowledged that Comcast would pay MASN roughly $\$ 1.25$ per subscriber per month to carry the Nationals games in the 2006 season (Mohammed, 2006). Thus, Comcast imposed a 60 percent markup on the marginal cost of MASN programming.

In assessing the potential anticompetitive effects, the FCC (2006b, p.116) found that the Adelphia-Time Warner/Comcast merger would increase the likelihood of harm to MVPDs in markets in which Time Warner or Comcast hold, or have the potential to hold, an ownership interest in an RSN. The FCC (2006b, p.116) also found that Time Warner and Comcast would gain an incentive and increased ability to deny carriage to unaffiliated RSNs. Regarding access to national or non-sports related programming, the FCC (2006b, p.167) found no likelihood of public interest harms and therefore declined to impose any remedial conditions. The FCC (2006b, p.141) concluded that even small increases in the market share of Comcast or Time Warner would increase the firm's incentives to increase 
prices for affiliated RSNs. In particular, the FCC (2006b, p.146) found that a uniform price increase was likely to occur in 15 of the 39 "key" geographic markets known as designated market areas (DMAs). The FCC (2006b, p.146) noted that DBS penetration levels are significantly lower when they cannot offer the local RSN to their subscribers.

The FCC recommended several conditions to prevent consumer harm. In particular, Comcast and Time Warner were prohibited from offering any RSNs on an exclusive basis to any MVPD; all covered RSNs must be made available to all MVPDs on a non-exclusive basis and on non-discriminatory terms. Moreover, Comcast and Time Warner cannot enter into any exclusive distribution agreements with any such RSN (FCC, 2006b, p.156). Intimidation of any non-affiliated RSN from entering into distribution agreements with rival MVPDs was also prohibited (FCC, 2006b, p.156). Mandatory commercial arbitration will be imposed in the result of any complaint by any party regarding compliance with these conditions (FCC, 2006b, p.163). Regarding concerns that the merger would give Comcast and Time Warner market power over unaffiliated national and regional programmers, including RSNs, the FCC (2006b, p.180) adopted a condition requiring commercial arbitration to resolve disputes about carriage on their systems.

This paper provides economic analysis in support of the FCC's merger conditions. It is organized as follows. In section 2, we review the relevant economic theory for assessing mergers and discriminatory behavior in MVPD markets. By denying access to its platform, cable operators with sufficient downstream market power can impair an unaffiliated video programming provider's efficiency or even induce exit. The ultimate goal of such a strategy is to control the distribution of that content so that rival MVPDs cannot compete as effectively in the downstream market.

In section 3, we apply the relevant theory to the acquisition of Adelphia by Comcast and Time Warner. Comcast is vertically integrated into sports programming and naturally favors its affiliated sports programming over unaffiliated sports programming. The merger increased Comcast's subscriber base in several local markets for sports programming, and it thereby increased Comcast's ability and incentive to deny access to unaffiliated sports programmers. If Comcast's strategy proves successful, MVPD customers who demand local sports programming would not be able to choose alternative downstream providers over Comcast. Finally, this strategy could undermine the planned entry by local telephone companies into video programming in geographic markets where the cable operator withholds its affiliated sports programming from rival MVPDs.

Section 4 presents a regression analysis that explains the variations in DBS penetration rates across local markets. We conclude that Philadelphia's low DBS penetration rate (roughly 9.4 percent) is less than what one would expect, given its demographic and economic characteristics, which suggests that Comcast's refusal to supply rival MVPDs with its affiliated RSN is likely the cause of Philadelphia's low DBS penetration rate. Combined with evidence that lower DBS penetration results in higher cable prices, this finding supports the view that foreclosure strategies will not only harm upstream unaffiliated programmers but may ultimately harm consumers as well.

\section{Theory of foreclosure in video programming markets}

An increase in a cable operator's base of subscribers increases its market power over unaffiliated programming providers in the upstream market for video programming. A 
cable operator with sufficient power in the downstream MVPD market can deny access to unaffiliated programmers, resulting in a programming rival's exit or impaired efficiency. In addition to the competitive injury of unaffiliated video programming providers, the abuse of that market power by cable operators would harm consumers of video programming through less competition (resulting in higher prices and less choice) in the downstream MVPD market, as unaffiliated video programming becomes affiliated programming, which is then withheld to rival MVPDs, particularly DBS operators.

Congress tried to address these competitive issues in the Cable Television and Consumer Protection Act of 1992 ("the Act") ${ }^{1}$, by prohibiting cable operators from discriminating against unaffiliated programming vendors and by requiring cable operators to provide access to affiliated content to rival MVPDs delivered via satellite. But these prohibitions are difficult to enforce, particularly because discrimination is hard to prove. In the context of RSNs, cable operators have thwarted Congress' objectives by extracting equity from unaffiliated programmers as a condition of carriage, and by delivering affiliated content - typically local sports programming - terrestrially over geographically contiguous networks so as to deny access to rival MVPDs. This practice makes it difficult for rival sports networks to gain a foothold, and it forces MVPD consumers who wish to see local sports programming to choose cable television over rival MVPD alternatives and to pay monopoly prices for such programming.

\subsection{Basic foreclosure theory}

The recent economic literature on foreclosure reveals that foreclosure is anticompetitive whenever it can impair a rival's efficiency and thereby impair a rival's ability to constrain prices, regardless of whether the rival is driven out of the market entirely (for example, Elhauge, 2003; Carlton and Waldman, 2002; Winston, 1990; Krattenmaker and Salop, 1986; Salop and Scheffman, 1983). Such foreclosure can create anticompetitive effects by depriving rivals of economies of scale, scope, distribution, supply, research, learning, or network effects (for example, Posner, 2005). With respect to economies of scope, anticompetitive foreclosure requires that the rival faces increasing marginal costs or large upfront costs or both. If the conduct forces the rival to operate on a higher portion of its marginal cost curve, then such conduct would achieve "partial foreclosure", and the rival would not be able to constrain prices as effectively. In the extreme case, when the conduct prevents the rival from covering its average variable costs, the conduct would induce exit and thereby achieve "complete foreclosure".

The goal of a vertically integrated cable provider is to maximize the joint profits of the upstream content division and the downstream distribution network. A vertically integrated cable provider can engage in "content discrimination" by refusing to carry unaffiliated programming. The cost of content discrimination is the potential loss in revenue from customers that demand the withheld content (for example, Rubinfeld and Singer, 2001a; Rubinfeld and Singer, 2001b). However, the refusal to carry the unaffiliated content can lead to the foreclosure of the downstream distribution rivals, allowing the cable provider to charge higher prices. If the increased revenue from higher prices offsets the potential decrease in revenue due to a loss in subscribers, then the vertically integrated cable provider will engage in content discrimination. Additionally, as the cable provider's

\footnotetext{
${ }^{1}$ Cable Television Consumer Protection and Competition Act of 1992, Pub. L. 102-385, 106 Stat. 1460 (codified in scattered sections of 47 U.S.C.).
} 
footprint grows, that is as it acquires competitors and their customers and moves into new regions, its incentive to engage in discrimination increases because of its ability to capture even greater revenues (Rubinfeld and Singer, 2001b, p.670).

\subsection{Foreclosure theory with endogenous downstream market share}

A vertically integrated cable operator with a sufficiently large share of the local MVPD market can thwart the development of, or extract concessions from, unaffiliated programming, and such actions can undermine competition in the downstream MVPD market. The ability to block the formation of a new RSN or to extract concessions from the RSN increases with the size of the cable operator's subscriber base. Geographically contiguous groupings of cable systems - called "clusters" - provide even greater market power. After choice content is secured (or affiliated programming is protected by blocking the formation of a rival), a vertically integrated cable operator can offset upstream losses (associated with a smaller distribution of content) with larger downstream profits (associated with higher prices after downstream rivals are foreclosed from procuring the choice content).

\subsubsection{Non-contiguous increases in subscriber base}

A video programming provider's bargaining power vis-à-vis a cable operator depends on several factors, including (1) the size of the cable operator's downstream footprint, (2) the cable operator's penetration rate within that footprint, and (3) whether the cable operator owns or partially owns competitive content. As the cable operator's downstream footprint increases, a video programming provider has fewer alternative outlets - that is, fewer cable customers nationwide - to whom it may distribute its content. As the cable operator's penetration rate within its footprint increases, a video programming provider again has fewer alternative outlets - that is, fewer DBS customers within the cable operator's footprint - to whom it might distribute its content. Finally, if the cable operator owns content (through affiliated programming providers) that is perceived by MVPD customers to be a close substitute for the content of an unaffiliated programming provider, then the cable operator has a strong incentive to discriminate against the rival, unaffiliated programmer to favor its affiliated programming provider and prevent the emergence of a genuine alternative for other downstream MVPD providers.

A merger between two non-overlapping cable operators increases the cable operator's footprint (effect \#1) and increases the likelihood that the cable operator will possess competing content within its expanded content portfolio (effect \#3). For example, suppose a cable operator in market $A$ purchased a home shopping program from a video programming distributor. Suppose further that the cable operator in market $A$ did not own competing content but the operator in market $B$ owned a home shopping network. After the merger, the content of the two operators is combined such that the operator in market $A$ now considers the unaffiliated home shopping network to compete with affiliated content of the merged firm.

Finally, to the extent that the merger can weaken downstream rivals (primarily DBS operators) by limiting access to affiliated content, a merger can further weaken the video programming provider's bargaining power by increasing the cable operator's penetration rate within its own territory (effect \#2). 


\subsubsection{Contiguous increases in subscriber base}

As noted above, a "cluster" is a combination of geographically contiguous cable systems. According to the FCC (2002a), the number of clusters covering a population in excess of 500,000 persons more than doubled during the 1990s, from 16 to 34. As of the end of 2003, slightly more than 53.6 million of the nation's 66.1 million cable subscribers were served by systems that were part of a cluster (FCC, 2005a). Clustering of territories allows incumbent cable operators to migrate affiliated programming from satellite delivery to terrestrial (fiber-optic) delivery, which is advantageous to cable operators because only satellite-delivered affiliated programming is subject to the program access rules created by the 1992 Cable Act ("the Act"). In its 2000 Cable Price Report, the FCC (2001) found that cable systems that were part of a cluster charged higher prices than cable systems that were not part of a cluster, even after controlling for other factors that might affect cable prices. The FCC (2002c) found similar results in its 2001 Cable Price Report. Several other studies have documented the deleterious effect of clustering on cable prices (General Accounting Office, 2000, p.28; Emmons and Prager, 1997) and on entry by overbuilders.

If an overbuilder believes that access to content that is demanded by MVPD customers within a given local market is not available due to an incumbent operator's ability to skirt the program access rules, then it will be disinclined to invest the sunk resources necessary to enter that market. The effect of overbuilder entry on cable prices is significant: the FCC's 2004 Cable Pricing Survey finds that monthly cable rates in January 2004 were 15.7 percent lower in areas where incumbent cable operators face competition from a wireline overbuilder (FCC, 2005d). Hence, to the extent that clustering deters entry by overbuilders, the effect of clustering is to maintain cable prices substantially above competitive levels. A merger that allowed an operator to increase the size of its clusters would have the same anticompetitive effect on consumer welfare.

\section{Application to the acquisition of Adelphia by Comcast and Time Warner}

With respect to the acquisition of Adelphia by Comcast and Time Warner, the proper way to examine the competitive effects is at the local level, as local sports franchises have predominantly local fans. By acquiring Adelphia, Comcast and Time Warner increased their respective subscriber bases in the local markets where Adelphia currently has subscribers.

\subsection{Defining the relevant geographic markets}

The Horizontal Merger Guidelines requires that agencies define product and geographic markets from the perspective of consumers (The U.S. Department of Justice and Federal Trade Commission, 1997). MVPD customers within a fixed geographic area are likely to share common preference with respect to sports franchises. For example, MVPD customers in Vienna, Virginia and Rockville, Maryland are more likely to support the Washington Nationals than, say, MVPD customers in Houston, who are more likely to have allegiance (to the extent that they are baseball fans) to the Houston Astros. A video programmer with rights to televise Washington Nationals' games could not generate the same revenues in Houston as he could in Washington. Because consumers in Houston do 
not consider Nationals games to be a substitute for Astros games, distribution of Astros and Nationals games are not in the same market.

The video programming industry has adopted its own geographic boundaries, known as DMAs, which the FCC routinely uses in its competition analysis of MVPD markets. Of the several DMAs affected by the acquisition of Adelphia by Comcast and Time Warner, we focused our attention on DMAs where (1) Comcast owned a local sports programming network and (2) the acquisition of Adelphia customers significantly increased Comcast's share of cable households.

With respect to the first criterion, Comcast owns or has a significant ownership share in at least eight RSNs: Bravevision (Atlanta DMA), Comcast SportsNet Philadelphia (Philadelphia DMA), Comcast SportsNet Chicago (Chicago DMA), Comcast SportsNet Mid-Atlantic (including the Washington and Baltimore DMAs), Comcast SportsNet West (Sacramento DMA), Comcast/Charter Sports Southeast (including the Miami DMA), Cowboys TV (Dallas-Ft. Worth DMA), and Falconvision (Atlanta DMA) (FCC, 2005a). Of the local markets in which Comcast has a presence in sports programming, the partial acquisition of Adelphia increased Comcast's subscriber base significantly in Washington, Baltimore, and Miami.

\subsubsection{The Washington DMA}

In 2005, Comcast estimated that it had 722,000 subscribers in the Washington DMA. It gained 238,000 subscribers from Adelphia to serve a total of 960,000 subscribers. Based on these estimates and data reported by Media Business Corp (2005a), Comcast controlled 70.7 percent (960,000 divided by 1.357 million) of all cable subscribers in the Washington DMA after its acquisition of Adelphia.

At the time of the merger proceeding, Comcast was involved in a dispute with MASN over the distribution of the Washington Nationals baseball games. The foreclosure theory outlined above explains the differing incentives of a vertically integrated cable operator and an unaffiliated programmer. MASN seeks to maximize the value of its rights to deliver Washington National games, which typically involves the distribution over multiple platforms within a given DMA, including DBS. MASN had reached a distribution agreement with DIRECTV for the Nationals. By contrast, Comcast considers the joint profits of its upstream content and downstream distribution network, which often involves offsetting upstream losses (associated with less distribution of affiliated content) with larger downstream profits (derived from higher prices after foreclosure of downstream rivals).

\subsubsection{The Baltimore DMA}

In the Baltimore DMA, Comcast estimated that it had 619,000 subscribers during the merger proceeding. Comcast gained 30,000 subscribers from Adelphia to serve a total of 649,000 subscribers in the Baltimore DMA. Based on these estimates and data reported by Media Business Corp. (2005a), there were approximately 667,000 cable subscribers in the Baltimore DMA. Hence, after its partial acquisition of Adelphia, Comcast controlled 97.4 percent $(649,000$ divided by 667,000) of all cable households in the Baltimore DMA.

In the Baltimore DMA, Comcast competes with MASN in the sports programming market. Under a contract that expired after the 2006 Major League Baseball season, Comcast SportsNet had a license to produce and exhibit Baltimore Orioles games. Under a settlement agreement reached with Major League Baseball, the holder of Orioles' telecast 
rights, TCR, will retain the rights to telecast Orioles games and will not license them to a third party video programming vendor such as Comcast SportsNet.

\subsubsection{The Miami DMA}

In the Miami DMA, Comcast estimated that it had 655,000 subscribers during the merger proceeding. Comcast gained 85,000 subscribers from Adelphia to serve a total of 740,000 subscribers in the Miami DMA. These estimates coupled with data reported by Media Business Corp. (2005a), there were approximately 787,000 cable subscribers in the Miami DMA. Hence, after its partial acquisition of Adelphia, Comcast controlled 94.0 percent (740,000 divided by 787,000) of all cable households in the Miami DMA.

At the time of the merger, two of the three statewide sports networks in Florida, FSN Florida and Sun Sports, were owned by Fox Sports Networks (Cobbs, 2005, p.15). Sun Sports had the telecast rights for the Miami Heat basketball team, and FSN Florida had the telecast rights for the Florida Marlins baseball team (Cobbs, 2005, p.15). Comcast and Charter owned Comcast/Charter SportsNet Southeast, which had the telecast rights to over 100 NCAA football games. ${ }^{2}$

\subsection{Assessing market power}

Market power is typically understood as a firm's ability profitably to raise prices above competitive levels for a non-transitory period, and thereby exclude rivals. Comcast increased prices and also excluded rivals in the Washington, D.C. DMA. According to the Washington Times (2002), Comcast increased monthly prices by 6 percent in the Washington area in 2003, which was consistent with a national trend among cable operators over the previous six years of an average increase of 45 percent. Comcast was excluding an upstream rival by its refusal to carry MASN. Moreover, although a high market share may not be sufficient to establish market power, after the merger, Comcast controlled 60 percent of the MVPD households in the Washington and Baltimore DMAs. This market share, which is double the share of the two DBS carriers combined, was effectively much higher when one considers that other incumbent cable operators served parts of the Washington DMA, which limited Comcast's maximum available market share of all MVPD households to well below 100 percent.

\subsection{Assessing the likely competitive effects on unaffiliated RSNs}

In its annual reports on the status of MVPD competition, the FCC has recognized the importance of sports programming in general and for MVPD entrants in particular. In its Eleventh Annual Report, the FCC (2005a, p.142) noted that "[s]ports programming warrants special attention because of its widespread appeal and strategic significance for MVPDs.” The FCC (2005a, p.166) reported that as of December 2004, RSNs represented approximately 40 percent of the 96 regional networks. According to small cable operators, sports channels were "the most costly services they distribute, with annual wholesale rate increases in excess of inflation” (FCC, 2005a, p.168). According to DIRECTV, clustering by cable operators was the reason that obtaining exclusive arrangements for valuable RSNs has become an increasingly viable and attractive proposition for cable operators (FCC, 2005a, p.168). According to Ameritech, a cable overbuilder in the mid-1990s, access to

\footnotetext{
${ }^{2}$ Comcast/Charter Sports Southeast, About Us (available at http://csssports.com/about_us.cfm).
} 
sports programming was "so essential to the success of a cable system that many operators will pay exorbitant prices and agree to entertain other less attractive business arrangements just to obtain it"(FCC, 1998a).

Comcast's refusal to provide access to MASN was motivated by a desire to extend its considerable market power from the downstream MVPD market to the upstream programming market. By denying Comcast cable subscribers in the Baltimore and Washington DMAs access to MASN's regional sports programming, Comcast ensured that MASN could not achieve minimum viable scale in the regional sports programming industry. If MASN could not generate sufficient revenues to pay down its significant fixed costs (including the lump sum payment to Major League Baseball for the television rights for the Nationals), MASN would be forced to exit the market and likely sell its television rights at a distressed price to Comcast. At that point, Comcast would have successfully extended its downstream market power into the upstream programming market. Among the MVPD providers in the Washington and Baltimore DMAs, Comcast would be willing to pay the most for those television rights given its 60 percent post-merger share of the downstream MVPD market.

Comcast's incentive to engage in content discrimination increases with the size of its downstream market share (Rubinfeld and Singer, 2001a, p.640). Applying a model to the broadband Internet access market, Rubinfeld and Singer demonstrated that a vertically integrated broadband operator would engage in content discrimination against an unaffiliated Internet portal so long as the gains from content discrimination (in terms of greater future affiliated content sales) exceeded the losses (in terms of fewer broadband access subscriptions). The vertically integrated broadband operator's incentives to engage in content discrimination increases with the size of its downstream market share because (1) the future gains in content sales after successful foreclosure of rival content providers would be spread over a larger base of broadband access customers and (2) a large downstream market share implies that rival downstream competitors cannot impose serious discipline on the pricing/carriage decisions of the vertically integrated provider. In particular, the vertically integrated broadband provider would accept a smaller increase in the price of its affiliated content - and still break even after engaging in content discrimination - given a larger downstream market share (Rubinfeld and Singer, 2001a, p.667).

\subsubsection{High switching costs}

That same analytical framework can be applied here to evaluate whether Comcast's incentive to engage in content discrimination increases with the size of its downstream market share. In this context, the relevant empirical question is whether Comcast's inregion market share would decline significantly as a result of Comcast's refusal to offer its cable subscribers access to MASN's regional sports programming. If the answer is "no", then Comcast would have stronger incentives to engage in content discrimination against MASN's regional sports programming after the merger. As demonstrated below, the answer is in fact "no", because although the ability to carry RSNs is critical to the success of MVPD entrants, few of Comcast's subscribers would be willing to switch to alternative MVPD providers merely to view Nationals' games.

The empirical evidence to date indicates that, in the Washington DMA, the cost to Comcast of refusing to carry MASN's regional sports programming is trivial. Using data from Media Business Corp., we analyzed the change in DBS subscriber levels in the 
Washington DMA for several quarters before and after Comcast announced that it would not offer its customers' access to MASN in the Washington DMA.

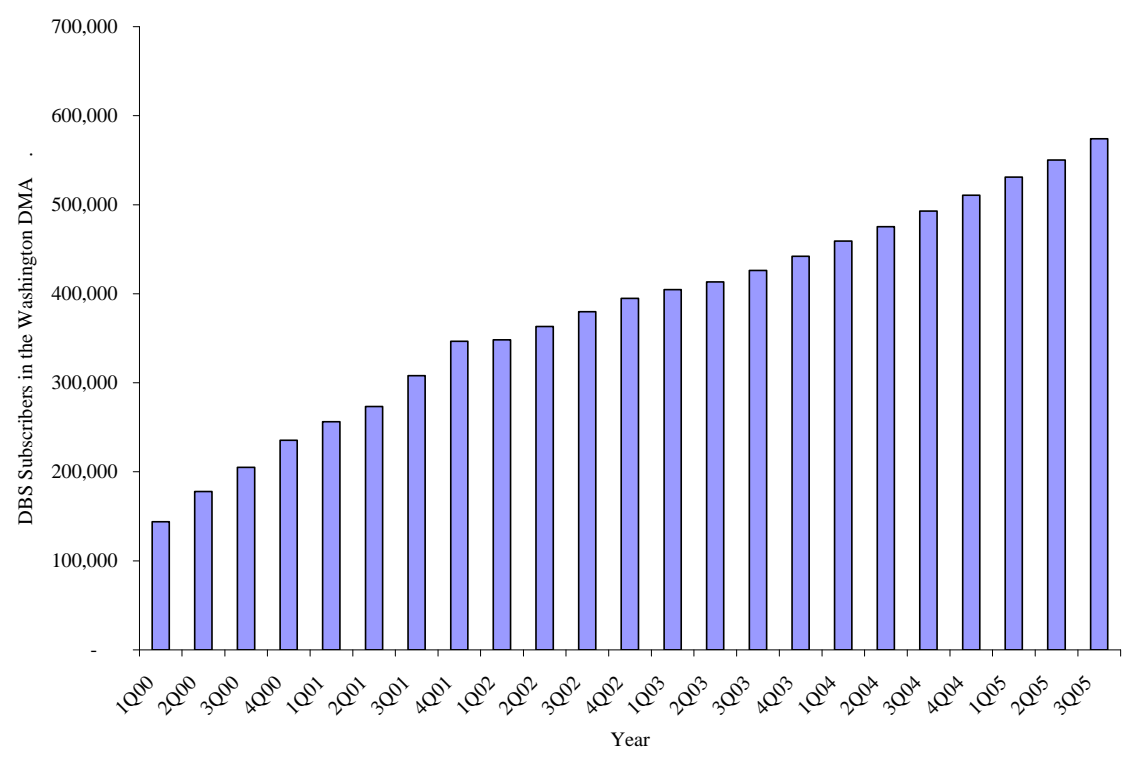

\section{Figure 1: DBS Subscribers in the Washington, D.C. DMA, 2000-05}

As Figure 1 illustrates, the average rate of increase of DBS subscribers in the Washington DMA declined after the fourth quarter of 2001 (13.5 percent average quarterly increase through the fourth quarter 2001 versus a 3.4 percent average quarterly increase after the fourth quarter 2001). The average increase in DBS subscribers in the third and fourth quarter of 2005 (3.9 percent) is less than the average increase from the first quarter 2000 through the first quarter 2005 (6.9 percent), and it is only slightly greater than the average increase from the first quarter of 2001 through the first quarter 2005 (3.3 percent).

Assuming that the unexplained portion of the increase in DBS subscribers in the Washington DMA in the second and third quarters of 2005 was due entirely to Comcast's refusal to carry MASN, Comcast's anticompetitive conduct caused it to lose only 6,000 subscribers per quarter due to Comcast's refusal to carry MASN. ${ }^{3}$ To put that in perspective, Comcast has over 800,000 cable customers in the Washington DMA according to Media Business Corp. Hence, even if all 12,000 unexplained DBS subscribers over the two quarters can be attributed to Comcast's foreclosure strategy, then the cost of that foreclosure strategy is trivial to Comcast: 12,000 subscribers account for less than two percent of all Comcast subscribers in the DMA.

The average quarterly increase in DBS subscriber penetration in the Washington DMA from the first quarter of 2000 to the first quarter of 2005 was 0.746 percent. Although the quarterly increase in DBS penetration in the third quarter (0.861 percent) is slightly higher than the average quarterly increases since the first quarter of 2000, that difference is not statistically significant. A t-test demonstrates that the increase in DBS penetration during the second and third quarters of 2005 was not statistically different from the mean quarterly increase in DBS penetration during the preceding period. Hence, there was no unexplained increase in DBS penetration in the Washington DMA that can be attributed to

\footnotetext{
${ }^{3}$ Equal to the actual increase in DBS subscribers in the second and third quarters of $2005(21,000)$ less the average increase in DBS subscribers in the prior twelve quarters $(15,000)$.
} 
Comcast's decision not to carry MASN. This empirical evidence confirms that, in the Washington DMA, the cost to Comcast of refusing to carry MASN's regional sports programming was trivial. ${ }^{4}$ To the extent that refusing to carry MASN produces any benefits for Comcast, the benefits from engaging in this foreclosure strategy outweighed the costs.

In addition to the empirical evidence that shows that customers have not in fact switched to satellite as a result of Comcast's discriminatory conduct, there are a number of reasons that explain why this is the case and likely to remain so. In particular, Comcast's cable customers must overcome significant switching costs to switch to satellite alternatives. A January 2005 empirical study by two FCC economists, Andrew Stewart Wise and Kiran Duwadi (2005, p.4), found that quality-adjusted prices for basic cable services must increase substantially to overcome the implicit or explicit costs of switching from cable to DBS. Wise and Duwadi (2005, p.21) explained that "in the multichannel video market, the incumbent cable operator commands a large market share, and cable subscribers may consider switching from cable to DBS as implying a perceived or real switching cost." They also explained that the cable incumbent's offering of additional services, such as high-speed Internet access and video-on-demand, would make the cost of switching to DBS higher than before for current cable subscribers (Wise and Duwadi, 2005, p.21). They concluded that "consumers switch multichannel video providers only in response to relatively large price changes, not small ones” (Wise and Duwadi, 2005, p.21).

Comcast's cable customers would not incur these significant switching costs so long as there was a non-trivial probability that Comcast and MASN would eventually reach an agreement. Consider a consumer who (1) believed that the probability that Comcast and MASN would reach an agreement before the end of the baseball season was 10 percent and (2) valued the ability to watch the 68 Nationals games' that were not televised on UPN, TBS, Fox, or ESPN at \$150. Hence, if the consumer switched to DIRECTV and incurred a switching cost of $\$ 150$ with certainty, then the consumer would refrain from switching because the expected benefit from remaining with Comcast (equal to 10 percent of $\$ 150$, or \$15) exceeded the expected benefit from switching to DIRECTV (equal to \$150 in incremental value less $\$ 150$ in switching costs, or $\$ 0$ ). Based on these five factors, it is reasonable to conclude that Comcast did not lose and would not lose market share as a result of its foreclosure strategy in Washington.

While the costs of switching from cable to satellite already are high, they also are likely to increase going forward because Comcast is increasingly able to offer consumers services that satellite providers cannot match - services such as high-speed data, voice, and video on demand. DBS providers are also at a disadvantage for video because consumers are shifting to watching high definition television (HDTV), which strains existing satellite capacity and requires additional equipment. For a DIRECTV customer to receive HDTV, the customer must install a new dish and antenna for local broadcast networks at a price of $\$ 300$. For the new dish to function properly, it must have a clear line of sight to three satellites simultaneously. Because a clear line of sight to three satellites simultaneously is

\footnotetext{
${ }^{4}$ Comcast was not the only cable operator in the Washington DMA that did not carry MASN. Because we are comparing the change in DBS penetration over successive quarters, however, the effects of other carriage decisions on DBS penetration should be negligible to the extent that those carriage decisions were constant over time. Moreover, Comcast's decision not to carry MASN had the greater potential to increase DBS penetration in the Washington DMA because Comcast and Adelphia collectively pass 65 percent of all homes in the DMA.
} 
much more difficult to obtain than a line of sight to a single satellite (the requirement for the first generation dish), DIRECTV will be seriously impaired in its ability to compete against Comcast for HDTV customers. ${ }^{5}$

Moreover, through its pricing of its cable modem service inside and outside the bundle, Comcast can create a strong inducement for its video subscribers to choose the entire array of services from its bundle. For example, Comcast (2006) charges D.C. residents $\$ 42.95$ per month for cable modem service when purchased as part of bundle with video service but charges a penalty price of \$57.95 per month for cable modem service when purchased on an a-la-carte basis. Subscribers who wish to purchase video service from a DBS provider and cable modem service must incur a penalty of $\$ 15$ per month. The DBS provider must compensate the subscriber for breaking the bundle, which may force its price for video service below its average variable cost. For this reason and many others, including the significant out-of-pocket costs of switching to DBS, Comcast could risk losing its D.C.-based customers by denying them access to Nationals' games on MASN.

Finally, the incentives for a customer to switch from cable to satellite are diminished here because the decision to remain a Comcast subscriber even when Comcast refuses to carry MASN does not preclude the subscriber from viewing all Nationals' games. Of the 162 Nationals games during the 2005 season, Comcast customers could see almost 50 percent, despite the fact that Comcast did not carry MASN. UPN 20 and Fox WTTG-5 carried 76 Nationals’ games (Nakamura and Heath, 2005). The national Fox Network carried four additional Nationals' games (Washington Post, 2005). ESPN and TBS each carried three Nationals' games. ${ }^{6}$ By comparison, when DIRECTV announced its deal with MASN, DIRECTV (2005b) said subscribers would receive 68 additional games via MASN. Hence, the value of switching to DIRECTV to watch Nationals' games is limited to the value associated with an incremental 68 games. Because even a baseball fan experiences diminishing marginal returns to watching baseball, the value of watching an additional 68 games is not as great as the value of watching the first 68 games. $^{7}$

\subsubsection{Relationship between downstream market power and discriminatory behavior in other markets}

Comcast's future behavior can be predicted in part based on its behavior vis-à-vis unaffiliated RSNs in the past. Table 1 shows each of the top 30 television markets (DMAs), as defined by Nielsen Business Media, in which Comcast owns a regional sports network (RSN). The table shows Comcast's downstream market shares in each DMA using two metrics - (1) the share of total households in the DMA that Comcast passes, and (2) the share of total households in the DMA that are Comcast subscribers (see FCC, 2005c). The table also indicates whether Comcast is engaging in content discrimination or conduit discrimination within the DMA. Table 1 demonstrates that Comcast engages in conduit discrimination against unaffiliated MVPDs in every market in which (1) it owns the sort of marquis sports content to make such discrimination worthwhile and (2) it supplies cable service to at least 35 percent of the households within the DMA.

\footnotetext{
${ }^{5}$ This information is based on the personal experience of one of the authors of this declaration, who attempted to purchase HDTV from DIRECTV without success during the summer of 2005 and was forced to switch to cable television.

${ }^{6}$ ESPN, MLB TV Listings, available at http://sports.espn.go.com/mlb/television?date=20030330\&network=ALL; Washington Post (2005).

${ }^{7}$ The "first 68 games" in this context refers to the first 68 games that the consumer is able to watch, rather than the first 68 games of the season chronologically.
} 
The three markets that satisfy these two conditions pre-merger are Philadelphia, Sacramento, and Chicago. Baltimore does not satisfy the first criterion because the rights to Washington Wizards basketball games or Washington Capitals hockey games cannot be considered marquis content in Baltimore. Although Comcast carries Baltimore Orioles baseball games on its Baltimore RSN through a licensing agreement with MASN, Comcast does not own the rights to this content (see Mitzer, 1996). Similarly, the first condition (ownership of marquis content) is not satisfied in Miami or Detroit.

Although the exact share of MVPD subscribers required to make conduit discrimination profitable is difficult to ascertain, based on the pattern contained in Table 1, it is reasonable to infer that the "critical share" is somewhere between 28 percent (premerger Washington DMA) and 35 percent (pre-merger Sacramento DMA). Because the merger increased Comcast's subscriber share in the Washington DMA to 38 percent, and because Comcast owns the television rights to the Wizards and Capitals (that is, the right of first refusal to distribute those games), following the merger the necessary conditions for conduit discrimination were satisfied in the Washington DMA.

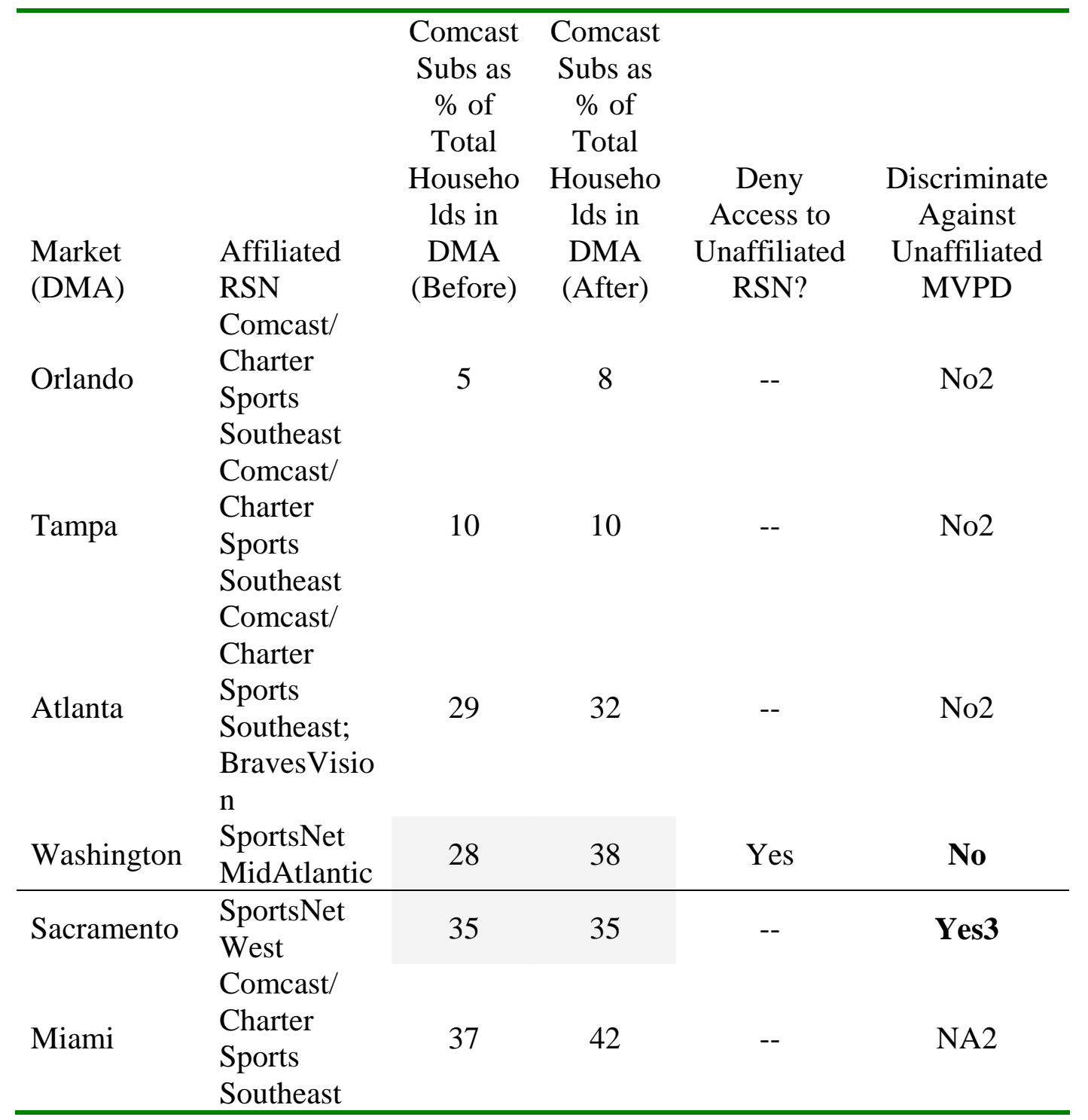




\begin{tabular}{|c|c|c|c|c|c|}
\hline Philadelphia & $\begin{array}{l}\text { SportsNet } \\
\text { Philadelphia }\end{array}$ & 58 & 60 & -- & Yes \\
\hline Baltimore & $\begin{array}{l}\text { SportsNet } \\
\text { MidAtlantic }\end{array}$ & 53 & 56 & Yes & NA4 \\
\hline Detroit & $\begin{array}{l}\text { Comcast } \\
\text { Local }\end{array}$ & 48 & 48 & No & NA 2 \\
\hline Chicago & $\begin{array}{l}\text { SportsNet } \\
\text { Chicago }\end{array}$ & 49 & 49 & -- & Yes5 \\
\hline
\end{tabular}

\section{Table 1: Top 30 local markets in which Comcast owns a RSN}

Notes: (1) In each DMA, the number of Comcast homes passed after the transaction is equal to either (a) the number of Comcast homes passed plus the number of Adelphia homes passed (for Washington, Miami, Baltimore, Atlanta, Orlando, and Tampa), or (b) the number of Comcast homes passed plus the number of Time Warner homes passed (for Philadelphia). (2) Comcast has yet to secure the marquis sports content (Major League Baseball, NBA basketball, or NHL hockey) that would put it in a position to discriminate against unaffiliated MVPDs in these markets. Comcast markets Comcast/Charter Sports Southeast as being exclusive to cable providers, and BravesVision as exclusive to Comcast digital cable subscribers. Comcast Local is also not carried by any DBS provider. (3) Requires DIRECTV to purchase SportsNet for a larger service area (beyond 150 miles of Sacramento). (4) Comcast carries Washington Wizards basketball and Washington Capitals hockey games on SportsNet MidAtlantic, but this cannot be considered marquis content in Baltimore. Although Comcast carries some marquis content in Baltimore (namely, Baltimore Orioles baseball games) on SportsNet MidAtlantic through a licensing agreement with MASN, Comcast does not own the rights to this content. MASN's contract with the Baltimore Orioles states that MASN has the "sole and exclusive right and license to produce and exhibit" Baltimore Orioles games on pay television. Hence, Comcast lacks the ability to withhold that content from DBS providers. (5) Comcast owns 30 percent of RSN only, which according to theory, would undermine its ability to engage in conduit discrimination. Upon acquiring the rights to sports programming, however, Comcast increased the price of this content by roughly 100 percent from what DIRECTV had been paying FSN Chicago for the same content.

Sources: Media Business Corporation, 2005a; Media Business Corporation, 2005b; Harding, 2005; DIRECTV, 2005a, pp.20,23-24; Charter/Comcast Sports Southeast, 2005; Dwyer, 2005; Mitzer, 1996.

For Comcast to have the incentive and ability to engage in conduit discrimination, it needed to own "marquee" professional sports content - live Major League Baseball, NBA basketball, or NHL hockey. The FCC previously recognized the importance of live professional sports content on an RSN to an MVPD when it granted the transfer of DIRECTV licenses from Hughes Electronics Corp. to News Corp.:

\footnotetext{
"At the outset, we agree with commenters that there are no reasonably available substitutes for News Corp.’s RSN programming and that News Corp. thus currently possesses significant market power in the geographic markets in which its RSNs are distributed. We base these conclusions, in part, on the limited number of teams and games of local interest that are available and [REDACTED], and on our economic analysis, described below, of the effects of temporary withdrawals of such programming from MVPD subscribers. An additional feature of RSN programming that sets it apart from general entertainment programming is the time-sensitivity of the airing of important local professional sports events, such as opening days or playoffs. As we have previously observed, RSNs are comprised of assets of fixed or finite supply - exclusive rights to
} 
local professional sports teams and events - for which there are no acceptable readily available substitutes. These peculiar features of RSN programming give rise to somewhat unique competitive problems in terms of finding relatively close substitute programming in the event access that is foreclosed to rival MVPDs” (FCC, 2004).

According to this definition, Comcast did not own marquee sports content in six of the ten DMAs: Miami, Atlanta, Tampa, Orlando, Detroit, or Baltimore (see Umstead, 2004, p.60; Multichannel News, 2004). However, Comcast's experience in the other three DMAs (not counting Washington) in Table 1 demonstrates that Comcast would discriminate against DBS providers once (1) Comcast secures the rights to marquee sports content and (2) established a large downstream footprint.

In Philadelphia, Comcast denies access to SportsNet Philadelphia to DBS providers through the so-called "terrestrial delivery" loophole (for example, DIRECTTV, 2005a, pp.16-17). Ever since Comcast acquired the rights to carry Philadelphia Phillies baseball, Philadelphia Flyers hockey, and Philadelphia 76ers basketball from SportsChannel Philadelphia and PRISM (a terrestrial network) in August 1997, Comcast has not negotiated with DBS providers regarding the right to carry SportsNet Philadelphia (FCC, 1998b).

Comcast also has shown that it does not need a terrestrial network to discriminate against other MVPDs. In Sacramento, Comcast requires DIRECTV to carry Comcast SportsNet West (“CSN-West”), which shows Sacramento Kings basketball games, in the San Francisco DMA, despite the fact that these games must be blacked out across this DMA (DIRECTTV, 2005a, pp.23-25). For DIRECTV to carry CSN-West, Comcast forced DIRECTV to carry the network in three "zones" - an inner zone consisting of areas in and around Sacramento, an outer zone consisting of areas within 150 miles of Sacramento, and an "outer-outer" zone consisting of the San Francisco DMA. Comcast charges the highest rates per subscriber for the inner zone, and charges lower rates for zones further out. Although Comcast charges the lowest per-subscriber rate for the outer-outer zone, the cost to DIRECTV to carry CSN-West in the outer-outer zone is enormous because that zone has twice as many subscribers as the inner and outer zones combined. As a result, the effective per-subscriber rate for subscribers who can view Kings games is much higher than the rates DIRECTV is required to pay for comparable marque RSN programming it obtains from Comcast (DIRECTTV, 2005a, p.24). DIRECTV has stated, for example, that the per-subscriber rates it is required to pay for CSN-West are higher than the rates it pays for FSN Bay Area - an RSN that carries live games for four men's professional sports teams. Comcast's ability to demand these high rates for content that cannot even be viewed in San Francisco derives from the fact that Comcast controls 97 percent of cable subscribers in the San Francisco DMA (DIRECTTV, 2005a, p.25). Thus, the impact of this overcharge is largely felt by DBS providers.

Likewise, Comcast discriminated against DBS providers in Chicago by means other than the terrestrial loophole. Comcast (2005c, p.50) launched Comcast SportsNet Chicago ("CSN-Chicago") with the Chicago Bulls, Blackhawks, Cubs, and White Sox in 2003. These teams previously were carried on FSN Chicago, an unaffiliated RSN. Once Comcast's RSN acquired the rights to these teams, Comcast demanded DIRECTV pay a rate for CSN-Chicago that was roughly 100 percent more than what DIRECTV had been paying FSN Chicago for the same content (DIRECTTV, 2005a, pp.20-21). Even if Comcast charged all MVPDs in Chicago this higher rate, the increased rates are discriminatory against Comcast's competitors because the largest MVPD in Chicago, 
Comcast, sees much of the rate increase as an intra-company transfer because of its 30 percent stake in CSN-Chicago (Dwyer, 2005).

A recent filing by Echostar (2005, pp.3-5) provides yet another way in which Comcast can potentially discriminate against a rival MVPD without relying on terrestrial delivery. According to Echostar (2005, p.5), Comcast blacked out NHL games on Comcast's Outdoor Life Network (OLN) when Echostar refused to capitulate to Comcast's 40 percent subscriber-penetration demands - that is, Comcast demanded that Echostar carry OLN on a tier to which at least 40 percent of Echostar's subscribed. This requirement has the effect of requiring the MVPD to carry OLN on its basic tier as a condition of carriage. Given the multiple anecdotes of conduit discrimination provided by DIRECTV and Echostar, it is reasonable to conclude that Comcast has the ability to discriminate against unaffiliated MVPDs without terrestrial delivery.

Finally, in its answers to the Commission's information request, Comcast (2005b, p.31) explains that it would be "economically infeasible to deploy a fiber network" to all of the headends contained within the footprint of its Chicago RSN. Comcast (2005b, p.31) also argues that satellite distribution is "more efficient" in the footprint of Comcast SportsNet MidAtlantic. Of course, these examples of discrimination provided by Echostar and DIRECTV suggest that terrestrial delivery is not a necessary condition for conduit discrimination. In any event, Comcast (2005b, pp.28-30) would not invest so heavily in deploying terrestrial networks over the past 15 years (the three-page list of geographic markets readied for terrestrial delivery was redacted by Comcast) if it was not planning on using those networks. Even if Comcast has no intention of using those networks, as it now claims, their mere existence of a terrestrial delivery system in those markets gives Comcast tremendous bargaining leverage over its MVPD rivals when it negotiates carriage of affiliated, marquee sports content.

\subsection{Efficiency defenses for Comcast's refusal to deal}

During the merger proceeding, Comcast (2005a) claimed that the cable ownership proceeding was the appropriate place to consider any concerns about regional concentration, and that Comcast had a number of rationales for not carrying MASN. In particular, Comcast argued that (1) Comcast and TCR could not agree on the incremental value of MASN, and (2) about half of the Nationals' games were broadcast on channels other than MASN. With respect to the first rationale, we understand that Comcast simply refused to deal with MASN: There was no dispute over the price of MASN. Thus, this defense was not compelling.

With respect to the second rationale, the fact that half of the Nationals' games were carried on other channels does in fact decrease the incremental value of MASN. But if carriage of Nationals' games on other networks decreased the incremental value of carrying MASN below MASN's asking price, then other MVPDs, such as RCN and DIRECTV, would not have carried MASN. There is no reason why a DIRECTV customer's willingness to pay for the additional 68 Nationals' games is significantly higher than a Comcast customer's willingness to pay for the additional 68 Nationals' games. Hence, one must reject the hypothesis that Comcast would be willing to accept MASN at a lower price (FCC, 2006b, p.189). 


\section{$4 \quad$ Estimating the effect of foreclosure on DBS penetration}

It is interesting that in the DMA where Comcast has adopted affiliation followed by foreclosure of rival MVPDs - in Philadelphia - the DBS penetration rate is less than half the average among the top 25 DMAs (9.45 percent versus 20.21 percent) (Media Business Corporation, 2005a) and cable television rates are higher. By August 1997, Comcast acquired all of the local telecasting rights of Philadelphia Flyers hockey games, Philadelphia 76ers basketball games, and Philadelphia Phillies baseball games previously held by the owner of SportsChannel (FCC, 1998b, p.21,834). Thereafter, SportsChannel announced that it would cease to operate as of September 30, 1997 (FCC, 1998b, p.21,834). On October 1, 1997, SportsNet debuted as a new channel on Comcast's basic service tier in the Philadelphia market area, and it was distributed only through terrestrial microwave and fiber technology (FCC, 1998b, p.21,834). Before introducing SportsNet as a new channel, Comcast indicated that SportsNet's programming would not be available to any national DBS provider (FCC, 1998b, p.21,834). DBS providers have never established a foothold in Philadelphia as a result of Comcast's foreclosure strategy.

In combination with securing the local telecasting rights for sports programming and delivering the signals terrestrially, Comcast expanded its cluster in the Philadelphia DMA through a series of swaps and acquisitions beginning in 1998, with the intent of expanding its capability to avoid the program access rules.

\footnotetext{
"As a result of these numerous acquisitions, Comcast now controls 91 percent of all cable households in the Philadelphia DMA (Media Business Corporation, 2005a). Moreover, Comcast thwarted RCN's entry in Philadelphia with aggressive pricing and intense lobbying efforts (Communications Daily, 2001, p.7; Philadelphia Inquirer, 2000), and Comcast has withheld regional sports programming from cable overbuilders and DBS providers. MVPD consumers in Philadelphia now pay more for expanded basic service: Comcast's prices for expanded basic service in Philadelphia have increased by 89 percent from 1999 to 2004 (Warren Communications, 1999; Warren Communications, 2004), whereas the average price for expanded basic service for all U.S. cable systems have increased by only 39 percent over the same time period” (FCC, 2005b).
}

Our hypothesis is that Comcast's conduct decreased DBS penetration in Philadelphia. Of course, DBS penetration in a given DMA is likely a function of many variables, which can be controlled for in a multi-variate regression analysis. To estimate the DBS penetration rate in Philadelphia "but-for" Comcast's conduct, we regressed (using a simple linear model) DBS penetration rates in a given DMA as of the first quarter 2005 on several demographic and economic characteristics of the DMA. We restricted the Philadelphia DMA from the sample. DBS penetration data by DMA were obtained from Media Business Corp. Demographic and economic data were obtained from the Census Bureau, and snowfall data were obtained from the National Oceanic and Atmospheric Administration (NOAA). The DMA boundaries were obtained from Geographic Data Technology (GDT). Table 2 shows the findings from a model without snowfall data.

As Table 2 shows, many of our explanatory variables were statistically significant at the 5 percent confidence level (absolute value of T-Stat greater than 1.95) and were of the predicted sign. DMAs in which a large percentage of the population (1) incurred long commutes, (2) was male, or (3) was college educated were more likely to observe higher DBS penetration rates. By contrast, DMAs in which a large percentage of the population (1) was poor, (2) was black, (3) lived in urban areas, (4) was not English-speaking, and (5) was older were more likely to observe lower DBS penetration rates. The adjusted R- 
squared of the regression was 0.41 . Using the regression coefficients and the demographic and economic characteristics of Philadelphia, our best point estimate for DBS penetration in the Philadelphia DMA is 15.4 percent. The 95 percent confidence interval around our best prediction is 13.1 to 17.8 percent. Because the actual DBS penetration rate in Philadelphia DMA is outside the 95 percent confidence interval, one must reject the hypothesis that Philadelphia's predicted penetration rate is 9.4 percent. Stated differently, Philadelphia's low DBS penetration rate is less than what one would expect given its characteristics, which suggests that Comcast's foreclosure strategy might be the cause of Philadelphia's low DBS penetration rate. Table 3 replicates these results with the snowfall variable.

\begin{tabular}{|c|c|c|}
\hline Variable & Coefficient & T-Stat \\
\hline Latitude & -0.000176 & -0.19 \\
\hline 30PlusCommute & 0.3532584 & 4.25 \\
\hline telephone penetration & -1.234347 & -2.62 \\
\hline poverty percent & -0.360956 & -2.03 \\
\hline percent urban & -0.211093 & -5.96 \\
\hline percent black & -0.115934 & -2.14 \\
\hline percent Asian speaking & -0.520003 & -2.89 \\
\hline $\begin{array}{l}\text { percent Euro speaking (non } \\
\text { Spanish) }\end{array}$ & -0.084917 & -0.76 \\
\hline percent Spanish speaking & -0.053423 & -0.94 \\
\hline percent male & 2.070555 & 3.62 \\
\hline percent college grad & 0.2032424 & 2.18 \\
\hline percent age 25-44 & -1.543885 & -3.96 \\
\hline percent age 45plus & -0.599612 & -3.42 \\
\hline Constant & 1.126015 & 2.19 \\
\hline
\end{tabular}

Table 2: Dependant variable is DBS penetration rate (specification without snowfall)

Note: Sample size was 209 (all DMAs except Philadelphia).

\begin{tabular}{|c|c|c|}
\hline Variable & Coefficient & T-Stat \\
\hline Snowfall & -0.000489 & -2.26 \\
\hline Latitude & 0.0013291 & 1.16 \\
\hline 30PlusCommute & 0.4041932 & 4.44 \\
\hline telephone penetration & -0.763383 & -1.34 \\
\hline poverty percent & -0.305442 & -1.55 \\
\hline percent urban & -0.170955 & -3.85 \\
\hline percent black & -0.125908 & -2.03 \\
\hline percent Asian speaking & -0.610874 & -3.41 \\
\hline $\begin{array}{l}\text { percent Euro speaking (non } \\
\text { Spanish) }\end{array}$ & -0.56194 & -2.6 \\
\hline percent Spanish speaking & -0.073769 & -1.11 \\
\hline percent male & 2.150846 & 3.15 \\
\hline percent college grad & 0.1764042 & 1.62 \\
\hline percent age 25-44 & -1.713199 & -3.9 \\
\hline
\end{tabular}




$\begin{array}{lll}\text { percent age 45plus } & -0.573333 & -2.88 \\ \text { Constant } & 0.6079258 & 0.94\end{array}$

Table 3: Dependant variable is DBS penetration rate (specification with snowfall)

Note: Sample size was 161 (all DMAs with readily available snowfall data except Philadelphia).

The adjusted R-squared of the second specification is 0.42 . Our best point estimate for DBS penetration in the Philadelphia DMA is 16.3 percent. The 95 percent confidence interval around our best prediction is 13.6 to 19.0 percent. Again, because the actual DBS penetration rate in Philadelphia DMA is outside the 95 percent confidence interval, one must reject the hypothesis that Philadelphia's predicted penetration rate is 9.4 percent.

In its Memorandum Opinion and Order, the FCC (2006a) found that the lack of access to RSN programming can seriously decrease an MVPD's market share, a key factor affecting a uniform price increase in RSN programming. The FCC (2006a) also rejected Comcast's claim that DIRECTV and Echostar had overstated the impact of not having CSN Philadelphia on their penetration rate. FCC research found that of the 210 DMAs, DBS penetration in those DMAs where the games of some of the local professional sports team were not available to DBS subscribers was significantly lower than when the DBS providers were able to carry the RSN (FCC, 2006a, p.146). For instance, DBS penetration for the 2004-1005 television season in San Diego was 9.5 percent, which was 59 percent below the national market share (FCC, 2006a, p.146).

The FCC (2006a, p.148) refers to two DBS studies that used regression analysis to estimate the effect of foreclosure on DBS penetration when the local RSN is unavailable to the DBS provider. DIRECTV used information on the number of DBS subscribers from Media Business Corp. to determine that in the Philadelphia region, DBS penetration would have been 51 percent higher but for the lack of CSN Philadelphia access; DIRECTV did not find a statistically significant effect from withholding RSN access in San Diego. A second study, by Echostar, found that its Philadelphia penetration would be significantly higher if it had access to the RSN.

Finally, the FCC's own regression analysis, which relied on its Cable Price Survey and Nielsen's data, found that the DBS penetration rate in Philadelphia was 40 percent below what it would be but for access to the RSN, and found that the DBS penetration rate in San Diego was 33 percent below what it should have been (FCC, 2006a, p.149). The FCC (2006a, p.151) concluded that a significant number of consumers will not purchase DBS service if it does not carry the local RSN.

\section{Conclusion}

Vertical foreclosure theories depend critically on the relevant geographic market. A local downstream access provider - whether it is a cable television operator or a cable modem provider - lacks the ability to foreclose an upstream content provider that generates content with nationwide appeal. Thus, the theories developed here are unique to local video programming markets, and they have little-to-no application in Internet content markets. Stated differently, a local cable modem provider with a miniscule share of national broadband customers lacks the ability to induce an Internet content provider from exiting the industry or even operating at an inefficient scale. Similarly, a local cable 
television provider with a miniscule share of national broadband customers lacks the ability to induce a national video programmer such as ESPN from exiting the industry or even operating at an inefficient scale.

Non-discrimination rules such as the kind imposed by the FCC in the ComcastAdelphia merger proceeding are needed in limited circumstances only. Theories of vertical foreclosure have been cited for support of this proposition in the net neutrality debate (van Schewick, 2007). However, this application of the theory of vertical foreclosure assumes incorrectly that a content provider is offering content that is particular to a given locality and therefore requires access to a single broadband provider's subscribers. The vast majority of Internet content appeals to all U.S. residents, not just the residents of a particular locality. This is precisely why anticompetitive refusals to deal are possible in video markets, where some content such as local broadcast television news and regional sports are in fact local, but impossible in Internet markets.

\section{$6 \quad$ References}

Carlton, D.W. and M. Waldman (2002) "The Strategic Use of Tying to Preserve and Create Market Power in Evolving Industries,” Rand Journal of Economics, 33: 194.

Cobbs, C. (2005) "Merged Networks at Top of Game Economies of Scale, Lack of Competitition Likely Will Boost Profits,” Orlando Sentinel, May 30.

Comcast Corporation (2005a) Applicant's Reply, In the Matter of Applications for Consent to the Assignment and/or Transfer of Control of Licenses, MB Docket No. 05-192.

Comcast Corporation (2005b) "Comcast Response to Information and Document Request," December 22.

Comcast Corporation (2005c) “SEC Form 10-K,” February 23.

Comcast Corporation (2006), January. http://www.comcast.com.

Comcast/Charter Sports Southeast (2005) "Frequently Asked Questions,” December 1. http://csssports.com/faqs.cfm

Communications Daily (2001) “Mass Media,” February 16.

DIRECTV (2005a) Comments of DIRECTTV, Inc., Applications of Adelphia Communications Corporation, Comcast Corporation, and Time Warner Cable Inc., for Authority to Assign and/or Transfer Control of Various Licenses, MB Docket No. 05-192, July 21.

DIRECTV (2005b) "DIRECTV is New Home For the Washington Nationals; MidAtlantic Sports Network and DIRECTV Reach Multi-Year Carriage Agreement for Carriage of Nationals Games,” April 29.

Dwyer, T. (2005) “Nats Caught in a TV Rundown,” Washington Post, June 28. 
Echostar Satellite, LLC (2005) Comments of Echostar Satellite, L.L.C., December 23.

Elhauge, E. (2003) "Defining Better Monopolization Standards," Stanford Law Review, 56: 253.

Emmons, W.M. and R.A. Prager (2002) "The Effects of Market Structure and Ownership on Prices and Service Offerings in the U.S. Cable Television Industry," Rand Journal of Economics, 28: 732.

Federal Communications Commission (1998a) Annual Assessment of the Status of Competition in the Market for the Delivery of Video Programming, CS Docket No. 98-102, 13 F.C.C. Rcd. 24282, 171.

Federal Communications Commission (1998b) In the Matter of DIRECTV, Inc. $v$. COMCAST Corporation, COMCAST-SPECTACOR, L.P., COMCAST SPORTSNET, 13 F.C.C. Rcd. 21,822, 21,826-27, Memorandum Opinion and Order, October 27.

Federal Communications Commission (2001) Statistical Report on the Average Rates of Basic Service, Cable Programming Service, and Equipment, MM Docket No. 92-266, 16 F.C.C. 4346, 42.

Federal Communications Commission (2002a) Annual Assessment of the Status of Competition in the Market for the Delivery of Video Programming, CS Docket No. 01-129, 17 F.C.C. Rcd. 1244, 67, Eighth Annual Report.

Federal Communications Commission (2002b) Annual Assessment of the Status of Competition in the Market for the Delivery of Video Programming, 17 F.C.C. Rcd. 1244, Eighth Annual Report.

Federal Communications Commission (2002c) Statistical Report on the Average Rates of Basic Service, Cable Programming Service, and Equipment, MM Docket No. 92-266, 17 F.C.C. 6301, 45.

Federal Communications Commission (2004) General Motors Corp., Hughes Electronics Corp. and The News Corporation Ltd., 19 F.C.C. Rcd. 473, 543.

Federal Communications Commission (2005a) Annual Assessment of the Status of Competition in the Market for the Delivery of Video Programming, CS Docket No. 04-227, 20 F.C.C. Rcd. 2755, 142, Eleventh Annual Report.

Federal Communications Commission (2005b) Implementation of Section 3 of the Cable Television Consumer Protection and Competition Act of 1992, Statistical Report on Average Rates for Basic Service, Cable Programming Service, and Equipment Report on Cable Industry Prices, MM Docket No. 92-266, February 4. http://hraunfoss.fcc.gov/edocs_public/attachmatch/FCC-05-12A1.doc

Federal Communications Commission (2005c) Statistical Report on Average Rates for Basic Service, Cable Programming Service, and Equipment, MM Docket No. 92-266, 20 F.C.C. Rcd. 2718, 2727, 25. 
Federal Communications Commission (2005d) Statistical Report on Average Rates for Basic Service, Cable Programming Service, and Equipment, MM Docket No. 92-266, 20 F.C.C. Rcd. 2718, 2727, 42.

Federal Communications Commission (2006a) in the Matter of Applications for Consent to the Assignment and/or Transfer of Control of Licenses, Adelphia Communications Corp. et al to Time Warner Cable Inc., et al, MB Docket No. 05-192, 145, Memorandum Opinion and Order.

Federal Communications Commission (2006b) In the Matter of Applications for Consent to the Assignment and/or Transfer of Control of Licenses, 20 F.C.C. Rcd. 8203, Memorandum Opinion and Order.

General Accounting Office (2000) "The Effect of Competition from Satellite Providers on Cable Rates.”

General Accounting Office (2003) "Telecommunications: Issues Related to Competition and Subscriber Rates in the Cable Television Industry,” October 24.

Goolsbee, A.D. and A.K. Petrin (2004) "The Consumer Gains from Direct Broadcast Satellites and Competition with Cable TV,” Econometrica, 72: 351.

Harding, A.H. (2005) Letter from Arthur H. Harding, Counsel for Time Warner Inc., to Marlene H. Dortch, Secretary, Federal Communications Commission, In the Matter of Applications of Adelphia Communications Corporation, Comcast Corporation, and Time Warner Cable Inc., For Authority to Assign and or Transfer Control of Various Licenses, MB Docket No. 05-192, June 21.

Krattenmaker, T.G. and S.C. Salop (1986) “Anticompetitive Exclusion: Raising Rivals' Costs to Achieve Power Over Price,” Yale Law Journal, 96: 209, 234-45.

Lenke, T. (2006) “MASN to Enter Arbitration,” Washington Times, July 14.

Media Business Corporation (2005a) "Basic and Digital Subscribers by DMA - 1st Quarter 2005.” Media Business Corporation.

Media Business Corporation (2005b) “Cable Homes Passed by DMA.” Media Business Corporation.

Mitzer, D.H. (1996) “Letter from Donald H. Mitzer, Group W Satellite Communications, to Peter G. Angelos, Baltimore Orioles Limited Partnership, Modifications to the Telecast Agreement between MASN and TCR Sports Broadcasting As Required by Major League Baseball,” October 9.

Mohammed, A. (2006) "Comcast To Raise Rate for Nationals; Subscribers to Pay \$2 a Month More,” Washington Post, August 12.

Mohammed, A. and T. Heath (2006) “Comcast Will Air Nats' Games, Ending Dispute,” Washington Post, August 5. 
Nakamura, D. and T. Heath (2005) "Nats’ TV Coverage Gets Upgrade,” Washington Post, April 8.

Philadelphia Inquirer (2000) "Philadelphia Cable TV Rates Rank with the Highest," October 15.

Posner, R.A. (2005) "Vertical Restraints and Antitrust Policy," University of Chicago Law Review, 72: 229.

Rubinfeld, D.L. and H.J. Singer. (2001a) "Open Access to Broadband Networks: A Case Study of the AOL/Time Warner Merger,” Berkeley Technology Law Journal, 16: 664.

Rubinfeld, D.L. and H.J. Singer. (2001b) "Vertical Foreclosure in Broadband Access," Journal of Industrial Economics, 49: 299.

Salop, S.C. and D.T. Scheffman (1983) "Raising Rivals' Costs," American Economic Review, 73: 267 (Special Issue).

Sidak, J.G. (2006) "A Consumer Welfare Approach to Net Neutrality Regulation of the Internet," Journal of Competition Law and Economics, 2: 349. http://jcle.oxfordjournals.org/cgi/reprint/2/3/349

Singer, H.J. (2002) “Does Clustering by Incumbent MSOs Deter Entry by Overbuilders?” Working Paper, Criterion Economics.

Supreme Court of the United States (2004) Verizon Communications, Inc. v. Law Offices of Curtis v. Trinko, 540 U.S. 398, 411-12.

The U.S. Department of Justice and Federal Trade Commission (1997) 1992 Horizontal Merger Headlines, April 8.

Umstead, R.T (2004) "Comcast, Braves Create HD Net; Regional Could Serve as Template for Other Dedicated Team Channels,” Multichannel News, September 27.

van Schewick, B. (2007) "Towards an Economic Framework for Network Neutrality Regulation,” Journal on Telecommunications and High Technology Law, 5: 329.

Warren Communications (1999) TV \& Cable Factbook; Warren Communications (2004), TV \& Cable Factbook.

Washington Post (2005) “Nats’ Schedule Still a Work In Progress,” April 17.

Washington Times (2002) “Comcast’s Gamble,” December 10.

Winston, M.D. (1990) “Tying, Foreclosure and Exclusion,” American Economic Review, 80: 837.

Wise, A.S. and K. Duwadi (2005) "Competition between Cable Television and Direct Broadcast Satellite - The Importance of Switching Costs and Regional Sports Networks," Journal of Competition Law and Economics, 1. 
